\title{
The Energy-Efficient Processing of Fine Materials by the Micropyretic Synthesis Route
}

\author{
H. P. Li \\ Jinwen University of Science and Technology, New Taipei City 23154, Taiwan \\ Correspondence should be addressed to H. P. Li, hli@just.edu.tw
}

Received 26 September 2011; Revised 28 November 2011; Accepted 2 December 2011

Academic Editor: William W. Yu

Copyright ( $) 2012$ H. P. Li. This is an open access article distributed under the Creative Commons Attribution License, which permits unrestricted use, distribution, and reproduction in any medium, provided the original work is properly cited.

Energy-efficient processing of $\mathrm{TiB}$ compound with nanowhiskers by micropyretic synthesis is investigated in this paper. Micropyretic synthesis not only offers shorter processing time but also excludes the requirement for high-temperature sintering and it is considered as the one of the novel energy-saving processing techniques. Experimental study and numerical simulation are both carried out to investigate the correlation of the processing parameters on the microstructures of the micropyretically synthesized products. The diffusion-controlled reaction mechanism is proposed in this study. It is noted that nanosize TiB whiskers only occurred when the combustion temperature is lower than the melting point of TiB but higher than the extinguished temperature. The results generated in the numerical calculation can be used as a helpful reference to select the proper route of processing nanosize materials. The Arrhenius-type plot of size and temperature is used to calculate the activation energy of $\mathrm{TiB}$ reaction. In addition to verifying the accuracy of the experimental measures, the reaction temperature for producing the micropyretically synthesized products with nanofeatures can be predicted.

\section{Introduction}

The micropyretic synthesis, or so-called combustion synthesis (CS) or self-propagating high-temperature synthesis (SHS), employs exothermic reaction processing, which circumvents difficulties associated with conventional methods of time- and energy-intensive sinter processing [1-17]. Two basic micropyretic synthesis modes are commonly employed, namely, the wave propagation mode and the thermal explosion mode. In the wave propagation mode, the compacted powders are ignited at a point by a heat source. After ignition, the heat to propagate the combustion wave is obtained from the heat released by the formation of the synthesized product. The unreacted portion in front of the combustion wave is heated by this exothermic heat, undergoes synthesis, the wave propagates, thus causing further reaction and synthesis, as shown in Figure 1. In the thermal explosion mode, the specimen is heated in a furnace. The furnace may be kept at the ignition temperature or the specimen may be heated in the furnace at a predetermined heating rate to the ignition temperature. The micropyretic reaction in this mode may occur more or less simultaneously at all points in the specimen. Although the synthesized product phases obtained by both techniques are similar [1], there may be differences in the amount of residual porosity, final dimensions, and the thermal gradient during the processing.

The advantages of micropyretic synthesis techniques include rapid net shape processing and clean products. When compared with conventional powder metallurgy operations, micropyretic synthesis not only offers shorter processing time but also excludes the requirement for high-temperature sintering. Volatile contaminants or impurities may be eliminated as the high temperature combustion wave propagates through the sample, and thus the synthesized products have the higher purity $[2,3]$. The steep temperature gradient also gives rise to the occurrence of metastable, nonequilibrium phases or nanosize features, which are not available in the conventional processing $[2,3]$.

In the past decades, the conventional powder processing routes or other techniques are used to synthesize the materials with the nanofeatures [18-22]. During the nanomaterial processing, there are three main difficulties for making reliable, uniform, nanostructure bulk alloys, including the following (1) The microstructural nonunifor- 
mity often occurred in the synthesized product. (2) Energy wastage impacts the cost of production. (3) Human safety is encountered when nanoparticles are processed during the synthesis. Micropyretic synthesis offers the rapid net-shape processing and clean homogeneous product and is thus considered as one of novel processing candidates to process the nano materials [10]. In this study, the micropyretic synthesis is used to process the nanosize materials.

Metal borides are a group of ceramic materials with outstanding and attractive properties for technological applications [8]. Among these materials, Ti-B compound differs with high electrical conductivity, and superconductivity at cryogenic temperatures. The formation of nanosize phase in the Ti-B brittle synthesize product can aid to enhance the mechanical properties dramatically and increase its application. In addition, Ti-B materials can also be synthesized in a net shape by micropyretic synthesis due to the higher exothermic heat. In the previous studies [15-17], we have found that the changes in the processing parameters have the significant impact on the properties of micropyretically synthesized products, including the formation of the nanosize features. Thus, the understanding of the processing parameters is important and can help to select the proper processing nanomaterial route during micropyretic synthesis. In this study, $\mathrm{Ti}+\mathrm{B}$ micropyretic reaction is chosen to study the effects of the processing parameters on the formation of nano size material. The experimental investigation and numerical calculation are both carried out to study the effects of processing parameters on the formation of nanosize $\mathrm{TiB}$ whisker in the micropyretically synthesized products.

1.1. Experimental Procedure. Ti+B micropyretic reaction is chosen to study the effect of processing parameters. Samples are obtained by mixing powders, pressing them into shape and finally combusting the shape by ignition from one end. The particle sizes of titanium and amorphous boron powders are both -325 mesh $(<44 \mu \mathrm{m})$. In order to retard the propagation velocity and further study the sequential reaction of Ti-B combustion, the larger B particle ( -60 mesh, $<250 \mu \mathrm{m})$ is also chosen in this study. The powders are first tumble mixed for $\sim 10$ minutes without the addition of any liquid medium. Subsequently, the well-mixed powders are pressed at $15000 \mathrm{psi}(-100 \mathrm{MPa})$, using a double-acting press and die to form an ASTM-ESM [23] standard specimen. The thickness and longitudinal length of the unreacted green compact are $5 \mathrm{~mm}$ and $90 \mathrm{~mm}$, respectively. For obtaining unidirectional wave propagation combustion, the compacted specimen is ignited from one end with an external heating source, which is held against the sample until combustion initiates. The heat source is then removed as the combustion front begins to propagate.

Microstructures are taken by scanning electron microscopy (SEM). For some of the microstructures, energy-dispersive analysis of X-ray (EDAX) is performed to obtain compositional data. X-ray diffraction (XRD) work is carried out in a Siemens diffractometer (model: D500) employing a $\mathrm{Cu}$ tube (wavelength: $0.15406 \mathrm{~nm}$ ) operating at $40 \mathrm{KV}$ and $30 \mathrm{~mA}$. Extremely fine $(\sim 100 \mu \mathrm{m})$ tungsten-rhenium

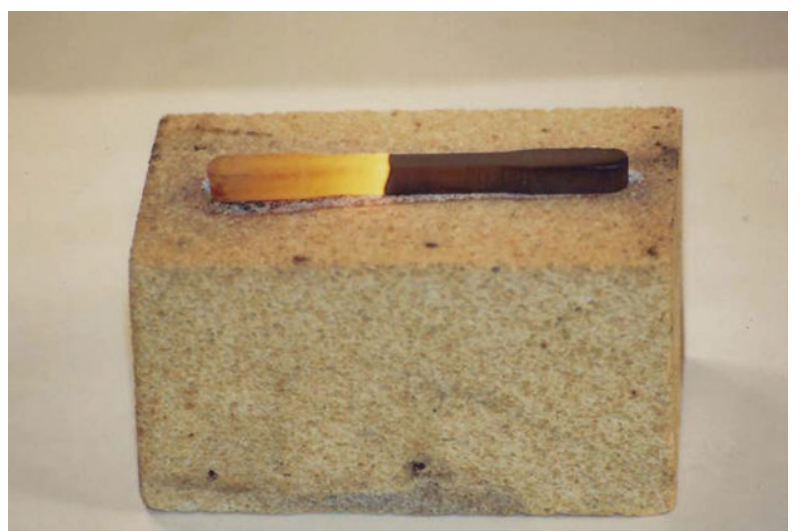

(a)

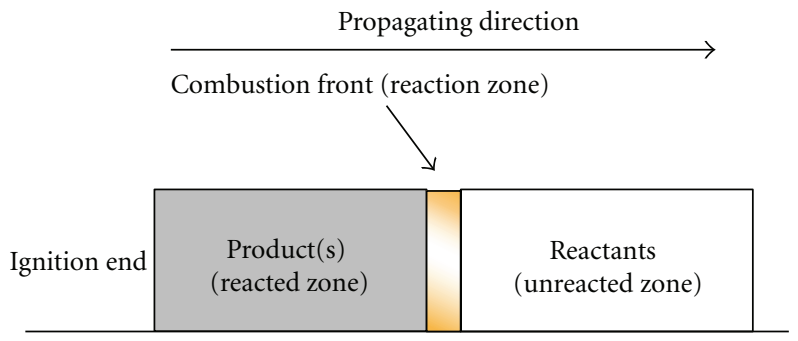

(b)

Figure 1: (a) The combustion front of the Ti-B reaction (with small $\mathrm{Cu}$ ) propagates from left to right after the ignition. (b) The schematic of the propagation of the combustion front in Figure 1(a). During the propagation, the sample can be divided into three different zones, including reacted zone, reaction melting zone, and unreacted zone.

(W- 5\% Re and W-26\% Re) thermocouples are used to measure combustion temperature and propagation velocity during the combustion reaction. The thermocouples are embedded in the central area of a sample, at a depth of half the sample height. A data acquisition system is used to record the temperature at every 0.1 -second interval. The combustion temperature is defined as the highest temperature during the combustion reaction. The average propagation velocity is calculated from the known distance between the thermocouples and the time lapse between the first signs of propagation of each thermocouple.

1.2. Numerical Simulation. During the passage of a combustion front in the micropyretic reaction, the energy equation for transient heat conduction, including the source term, containing heat release due to the exothermic reaction is given as $[6,12,13]$

$$
\rho C_{p}\left(\frac{\partial T}{\partial t}\right)=\frac{\partial}{\partial z}\left(\kappa\left(\frac{\partial T}{\partial z}\right)\right)-\frac{4 h\left(T-T_{o}\right)}{d}+\rho Q \mathcal{Q} \Phi(T, \eta) .
$$

Each symbol in the equation is explained in the nomenclature section. The reaction rate, $(T, \eta)$, in (1) is given as

$$
\Phi(T, \eta)=\frac{\partial \eta}{\partial t}=K_{o}(1-\eta) \exp \left(-\frac{E}{R T}\right) .
$$


TABLE 1: The thermophysical/chemical parameters for the reactants and product at sold state $(300 \mathrm{~K})$ and liquid state [24].

\begin{tabular}{lccc}
\hline Thermophysical/chemical parameters & $\mathrm{Ti}$ & $\mathrm{B}$ & $\mathrm{TiB}_{2}$ \\
\hline Heat capacity $(300 \mathrm{~K})(\mathrm{J} /(\mathrm{kgK}))$ & 528 & 118 & 950 \\
Heat capacity (liquid) $(\mathrm{J} /(\mathrm{kgK}))$ & 700 & 2800 & 2055 \\
Thermal conductivity $(300 \mathrm{~K})(\mathrm{J} /(\mathrm{msK}))$ & 21.6 & 27 & 25 \\
Thermal conductivity $($ liquid $)(\mathrm{J} /(\mathrm{msK}))$ & 11 & 15 & 13 \\
Density $(300 \mathrm{~K})\left(\mathrm{kg} / \mathrm{m}^{3}\right)$ & 4500 & 2450 & 4400 \\
Density (liquid) $\left(\mathrm{kg} / \mathrm{m}^{3}\right)$ & 4110 & 2080 & 4100 \\
\hline
\end{tabular}

TABLE 2: The values of various parameters used in the numerical calculation $[25,26]$.

\begin{tabular}{lc}
\hline Parameters & $\mathrm{TiB}_{2}$ \\
\hline Combustion temperature $(\mathrm{K})$ & 3190 \\
Activation energy $(\mathrm{kJ} /$ mole $)$ & $318[25]$ \\
Exothermic heat $(\mathrm{kJ} / \mathrm{mole})$ & $4214[26]$ \\
Preexponential factor $(1 /$ second $)$ & $1 \times 10^{10}$ \\
\hline
\end{tabular}

In this study, a numerical calculation for (1) is carried out with the assumption of the first-order kinetics. In (1), the energy required for heating the synthesized product from the initial temperature to the adiabatic combustion temperature is shown on the left-hand side. The terms on the right-hand side are the conduction heat transfer term, the surface heat loss parameter, and the heat release due to the exothermic micropyretic reaction, respectively. The previous two-dimension study [12] has indicated that the conduction heat transfer and surface heat loss are so small as compared with the exothermic heat. Thus, the surface heat loss is assumed to be radically Newtonian and is taken to be zero in this study.

A middle-difference approximation and an enthalpytemperature method coupled with Gauss-Seidel iteration procedure are used to solve the equations of the micropyretic synthesis problems. In the computational simulation, a one-dimensional sample of $1 \mathrm{~cm}$ long is divided into 1201 nodes (regions) to calculate the local temperature. This one-dimensional numerical model assumes the following sequence of events: (1) the specimen is gradually heated by a surface heat source; (2) the reaction is ignited and the combustion front propagates along the specimen; (3) there is a cooling source at one end. The choice of $1 \mathrm{~cm}$ sample length is only for computational purpose, and the simulation results are applicable to practical experimental conditions. The proper initial conditions are used to initialize the temperatures and enthalpies at all nodes. At time $t=0$, the temperatures are taken to be the same as the substrate temperature $\left(T=T_{\mathrm{o}}(300 \mathrm{~K})\right.$ and $\left.\eta=0\right)$. The energy is gradually added at the ignition node in very small time steps until the combustion front starts to propagate.

The various microscale events, that is, local processes such as warming of the sample, melting of lower refractory reactant, formation of product, and cooling of the sample at one end, are included in this calculation procedure. Depend- ing on the values of the temperature and enthalpy occurring in the reaction, the proper thermophysical/chemical parameters are considered and the limits of the reaction zone are determined for each node in the numerical calculation. At any given time, the fraction reacted and enthalpy of the current iteration are calculated from the previous fraction reacted and enthalpy of the earlier iteration. The range of the enthalpy as well as the molar ratio among each material for each node is thus determined, and the values of temperature, density, and thermal conductivity at each node can be further calculated in appropriate zone.

The various thermophysical/chemical parameters, such as thermal conductivity, density, and heat capacity of the reactants and product, are assumed to be independent of temperature, but they are different in each state. The average values of these parameters vary as the reaction proceeds, depending upon the degree of reaction. The parameter values used in the computational calculation are shown in Table 1 [24] and Table $2[25,26]$. In this study, the combustion temperature is defined as the highest reaction temperature during micropyretic synthesis, and the propagation velocity is the velocity of the combustion front propagation. In addition, the higher preexponential factor $\left(K_{\mathrm{o}}\right)$ value, $1.0 \times$ $10^{10} \mathrm{l} / \mathrm{s}$, is used to be capable of illustrating the variation of the propagation velocity for the Ti-B micropyretic reaction.

\section{Results and Discussion}

2.1. Ti-B Micropyretic Reaction. It has been proposed that the micropyretic/combustion synthesis includes the diffusion and the capillary-controlled reaction mechanisms, which are dependent on the size of the reactant particle [27-29]. Following the study of Nekrasov et al. [29], the diffusion control is dominant when

$$
d_{l}^{2} \ll \frac{2 \sigma \lambda d_{h}}{\mu \nu^{2}} * \ln \left[\frac{T_{c}-T_{o}}{T_{m}-T_{o}}\right]
$$

where $d_{l}$ and $d_{h}$ are the diameters of the particle sizes for the low melting point component and high melting point component, respectively. The other symbols and the values of the variables used for calculating (3) are shown in Table 3 $[24-26,30]$. The Ti particle (low melting component) size threshold between the diffusion-controlled and the capillarycontrolled combustion propagation may be thus calculated using (3). Employing (3), we note that the diffusion control can take place when the B size (diameter) should be higher 
TABle 3: The thermophysical/chemical parameters for the molten $\mathrm{Ti}$ (at $1933 \mathrm{~K}$ ) used in the calculation of (3) [24-26, 30].

\begin{tabular}{lll}
\hline$\Sigma$ & Surface tension & $1.46 \mathrm{~N} / \mathrm{m}$ \\
$\Lambda$ & Thermal diffusivity, [= K/(D.C $)]$ & $4.4 \times 10^{-6} \mathrm{~m} 2 / \mathrm{s}$ \\
$K$ & Thermal conductivity & $13 \mathrm{~J} /(\mathrm{m} \cdot \mathrm{s} \cdot \mathrm{K})$ \\
$D$ & Density & $4300 \mathrm{Kg} / \mathrm{m}^{3}$ \\
$C_{p}$ & Heat capacity & $682 \mathrm{~J} /(\mathrm{Kg} \cdot \mathrm{K})$ \\
$\mu$ & Viscosity & $0.002 \mathrm{~s}\left(\mathrm{~N} / \mathrm{m}^{2}\right)$ \\
$T_{m}$ & Melting point & $1933 \mathrm{~K}$ \\
$v$ & Propagation velocity & $0.02 \mathrm{~m} / \mathrm{s}$ \\
$T_{o}$ & Initial temperature & $300 \mathrm{~K}$ \\
$T_{c}$ & Combustion temperature & $2700 \mathrm{~K}$ \\
\hline
\end{tabular}

than $0.14 \mathrm{~nm}$ for $30 \mu \mathrm{m} \mathrm{Ti}$. The boron sizes we used in this study are in the microscare $(-60$ mesh and -325 mesh, $<250 \mu \mathrm{m}$ and $<44 \mu \mathrm{m}$ ) and are much higher than the correspondingly calculated critical size. Thus the studied mixtures are expected to be all in the range of diffusioncontrolled combustion.

For investigating the possible titanium boride reaction mechanism in the Ti-B binary system, a sample with larger B particles $(-60$ mesh $(<250 \mu \mathrm{m}))$, which propagates at a lower velocity, is intentionally extinguished during the propagation. It is inferred from microstructures that as the combustion starts, the unreacted portion in front of the combustion front is preheated by the released energy. The temperature of the unreacted portion is increased to a high level, melting the less refractory phase (Ti). The molten Ti encapsulates the nonmelting B particles (Figure 2). The resultant increase in the contact area between $\mathrm{Ti}$ and $\mathrm{B}$ significantly increases the reaction kinetics. The reacted product subsequently forms a layer on the surface of the nonmelting B particle. The exothermic heat of the product formation is released and conducts to unreacted materials, which in turn react, continuing the chain reaction.

From the diffusion-control mechanism theory and the observed microstructures (Figure 2), we propose the following reaction sequences for Ti-B reaction. (1) The Ti particles first melt and flow around the B particles. (2) The contact efficiency of B particles with the Ti liquid is now increased and the molten Ti ignites the rapid reaction. (3) An intermediate complex forms. (4) The Ti atoms diffuse from the melt, across the complex, to readily react with the $\mathrm{B}$ particle at its surface. (5) The intermediate complex of reaction is dissolved on the Ti-liquid side. Fresh new intermediate complex phase is formed between the intermediate complex phase and $\mathrm{B}$ particle at such a rate that the thickness of the complex is a constant. (6) The final Ti-B stoichiometric product is then precipitated from the molten liquid.

Figures 3(a) and 3(b) show the microstructures for the Ti-B reactions with the different compositions. Note from Figure 3 that microstructures are significantly changed when the composition is varied from $10 \mathrm{wt} \% \mathrm{~B}$ to $25 \mathrm{wt} \% \mathrm{~B}$. The formation of the nanosize feature is only observed in the composition with $10 \mathrm{wt} . \%$ B. The average measured propagation velocity for the composition with $25 \mathrm{wt} . \%$

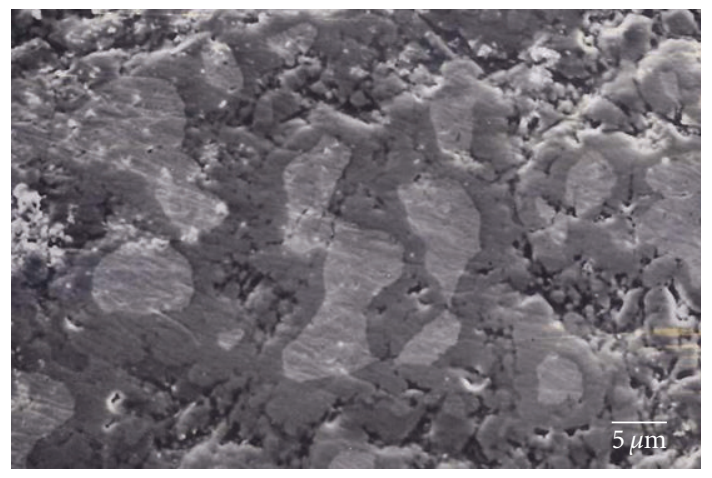

Figure 2: SEM morphologies of the Ti-B reacted zone. As the combustion commences, when the temperature of the unreacted portion is increased to a high level, the less refractory phase (Ti) is first melted. The molten Ti then encapsulates the nonmelting $\mathrm{B}$ particles and the resultant increase in the contact area between $\mathrm{Ti}$ and $\mathrm{B}$ dramatically increases the reaction kinetics. The reacted product subsequently forms on the surface of the nonmelting B particle.

B $(>20 \mathrm{~cm} / \mathrm{s})$ is much higher than that for composition 10 wt. $\%$ B $(0.96 \pm 0.32 \mathrm{~cm} / \mathrm{s})$. The combustion temperature for the composition with $25 \mathrm{wt} . \% \mathrm{~B}$ exceeds the upper limit of thermocouples, and the combustion temperature is increased with the increase in the propagation velocity, as shown in Table 3. These experimental demonstrations show that the changes in the processing parameters influence the combustion temperature and propagation velocity, further altering the microstructures and properties of the synthesized products. To understand the processing parameters as nanosize structures form, the computer simulation is then used to aim towards an understanding.

\subsection{Numerical Study Is Used to Forecast the Formation of} Nanosize Structures. The previous experimental and numerical studies $[12,15,16]$ have shown that the processing parameters, including the initial temperature, reactant particle size, diluents, compact density, compositions, exothermic heat, and activation energy have a significant impact on the reaction parameters, like propagation velocity and combustion temperature. A change in the reaction parameters has significantly influenced the properties of the synthesized products. It is noted that the combustion temperature and propagation velocity are increased as increasing the initial temperature or exothermic heat or are decreased as increasing the reactant size, activation energy, or amount of the diluents.

Figure 4 shows the numerical calculating results for the temperature-time plots for the compositions with the different processing parameters (different values of activation energy). The micropyretic reactions are ignited by ignition power (per gram) of $175 \mathrm{Joule} /(\mathrm{ms} \cdot \mathrm{g})$ at the position $0 \mathrm{~cm}$, and the heating sources are removed immediately after the combustion front has been ignited. The interval time between two consecutive time steps (profiles) in Figure 4 is $0.001 \mathrm{~s}$. It is found from Figure 4 (b) that the combustion 


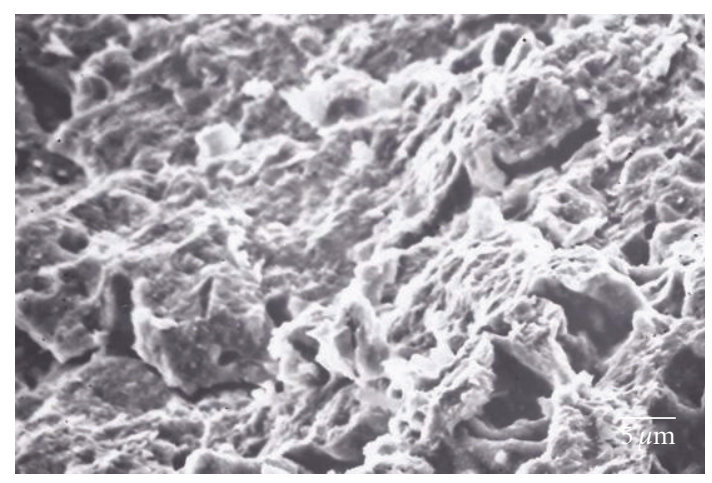

(a)

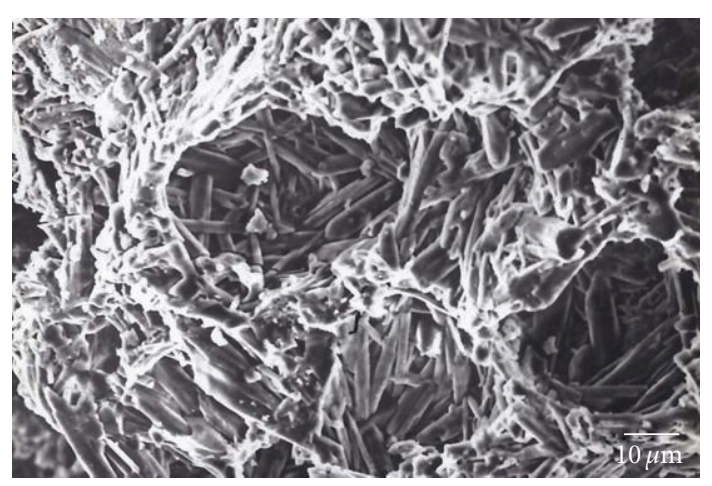

(b)

FIgURE 3: SEM morphologies of the Ti-B reacted zone. (a) Ti +25 wt. $\%$ B combustion and (b) Ti +10 wt. $\%$ B combustion.

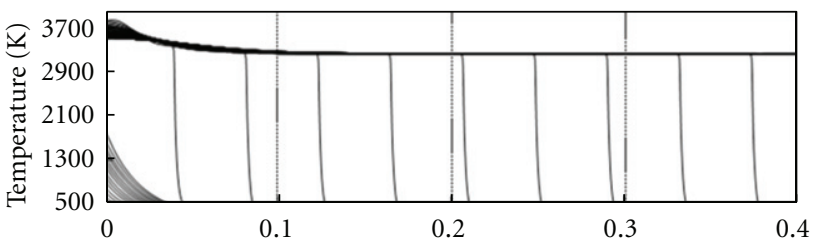

(a)

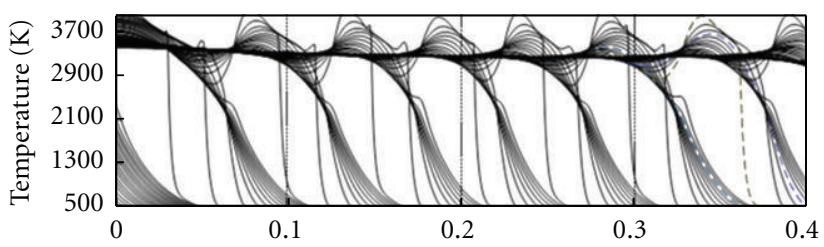

(b)

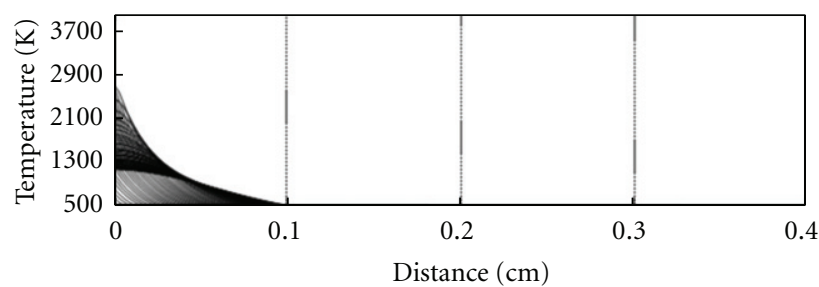

(c)

Figure 4: Time variations of the combustion front temperature along the $\mathrm{TiB}_{2}$ specimen with the preexponential factor of $1 \times 10^{10} \mathrm{~s}^{-1}$. The interval time between two consecutive time steps (profiles) is $1.0 \mathrm{~ms}$. The ignition power is taken as $175 \mathrm{Joule} /(\mathrm{ms} \cdot \mathrm{g})$ in the numerical calculation. The activation energy in (a), (b), and (c) are taken as $254.4 \mathrm{KJ} / \mathrm{mole}$ ( $80 \%$ of reported experimental value) [27], 318.0 KJ/mole (reported experimental value), and $381.6 \mathrm{KJ} / \mathrm{mole}$ (120\% of reported experimental value), respectively.

front takes $21.04 \mathrm{~ms}$ to start propagating for the Ti-B micropyretic reaction with the reported experimental activation energy $(318 \mathrm{KJ} / \mathrm{mole})$ [27]. This ignition time interval corresponds to the ignition energy of 3682.0 Joule/g. Figure 4 (b) also displays an alternating increase and decrease in the temperature and propagation velocity during the combustion front propagation, indicating that the combustion front for Ti-B micropyretic reaction propagates in an unstable oscillatory manner. When $80 \%$ of reported experimental activation energy value is taken in the numerical calculation, the propagation manner is noted to change from unstable manner to stable manner; in addition, the ignition time is reduced from $21.04 \mathrm{~ms}$ to $16.38 \mathrm{~ms}$, which corresponds to the ignition energy of 2866.5 Joule/g (Figure 4(a)). When $120 \%$ of reported experimental activation energy is taken in the calculation, the ignition time is increased to $25.66 \mathrm{~ms}$ (corresponding to the ignition energy of $4490.5 \mathrm{Joule} / \mathrm{g}$ ) and the combustion front extinguishes immediately after the start of propagation (Figure 4(c)).
It is known that the decrease in the propagation velocity reduces the oscillating combustion temperature. A further decrease in the velocity may extinguish the propagation of the combustion front. The study of Borovinskaya et al. [8] also shows the oscillating patterns for Ti- (and Ta-, $\mathrm{Nb}-, \mathrm{Zr}-$ ) $\mathrm{B}$ reaction. Thus, the above results generated from the above numerical demonstrations indicate that the nanowhisker formation can be acquired only at the low reaction temperature but without stopping the chain reaction. This study next tries to select the proper reaction temperature to synthesize the nanosize material by changing the reactant compositions.

\subsection{Selection of the Proper Processing Parameters to Synthesize} Nanosize Products. Figure 5 shows the SEM morphologies of the synthesized products with different boron content. It is noted from Figure 5 and Table 4 that the sizes of the whiskers are decreased with the decrease in the combustion 


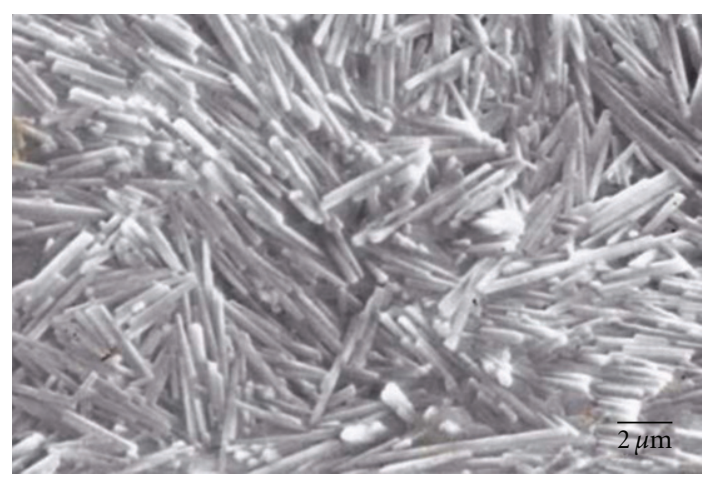

(a)

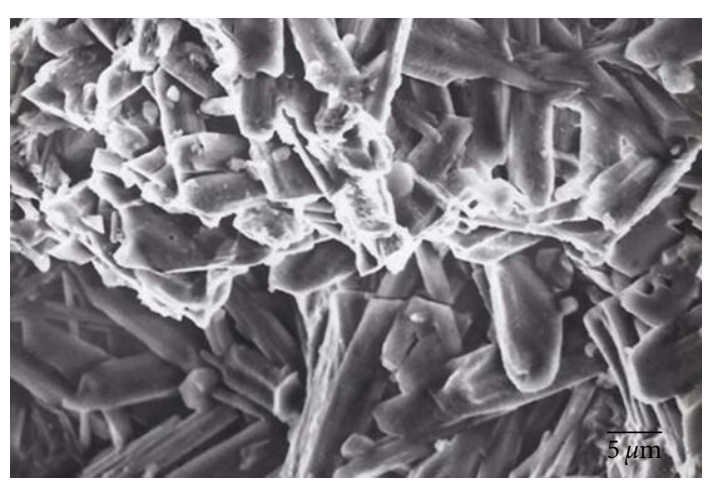

(b)

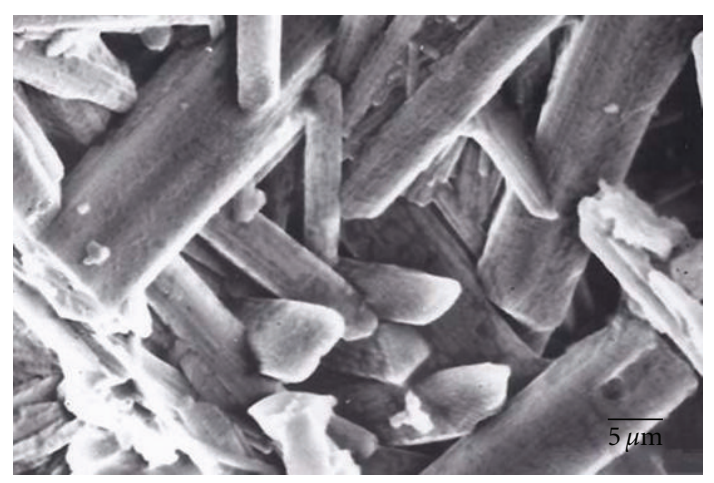

(c)

Figure 5: SEM morphologies of the Ti-B whiskers. (a) Ti +10 wt. \% B combustion and (b) $\mathrm{Ti}+17.5$ wt.\% B (b) Ti + 20 wt.\% B combustion.

TABLE 4: The combustion temperature, propagation velocity, and the diameter of whisker for the compositions with different boron contents.

\begin{tabular}{lccc}
\hline Boron content $($ wt. $\%)$ & Combustion temperature $(\mathrm{K})$ & Propagation velocity $(\mathrm{cm} / \mathrm{s})$ & Diameter of whisker $(\mu \mathrm{m})$ \\
\hline 25.0 & $>2100$ & $>20$ & NA \\
20.0 & $1980 \pm 26$ & $8.52 \pm 1.52$ & $6.96 \pm 2.18$ \\
17.5 & $1845 \pm 18$ & $7.12 \pm 1.46$ & $3.96 \pm 1.57$ \\
15.0 & $1672 \pm 11$ & $1.92 \pm 0.84$ & $1.65 \pm 0.46$ \\
10.0 & $1513 \pm 15$ & $0.96 \pm 0.32$ & $0.64 \pm 0.35$ \\
\hline
\end{tabular}

temperature. The new nonwhisker structures are observed when the combustion temperature exceeds $2100 \mathrm{~K}$. It is expected that the average measured combustion temperature of composition with $25 \mathrm{wt} . \% \mathrm{~B}$ is much higher than the melting point of TiB phase. The TiB whiskers may be melted and then solidified. The nonwhisker microstructure is thus formed.

The whisker structures are further analyzed by XRD. The X-ray patterns show that the whisker structures tend to be the TiB phase. Similar Ti-B whisker morphologies have also been observed in several studies [31-34]. In the study of Andrievskii et al. [31], it was shown that $\mathrm{TiB}_{2}$ (hexagonal type) and $\mathrm{TiB}$ (orthorhombic type) are probably characterized by anisotropy of surface energy, and consequently the grains are expected to be faceted. Hashimoto et al. [32] found that at sintering temperatures of $1373 \mathrm{~K}$, and $1473 \mathrm{~K}$ the needle- or fiber-type $\mathrm{TiB}_{2}$ precipitates when the coarse B powder $(\sim 150 \mu \mathrm{m})$ is chosen. Hyman et al. [33] performed extensive as-cast-binary as well as TEM studies on the formation of $\mathrm{TiB}$ and $\mathrm{TiB}_{2}$ in the ternary $\mathrm{Ti}-\mathrm{Al}-\mathrm{B}$ system.
It was shown that the crystal structures of both $\mathrm{TiB}$ and $\mathrm{TiB}_{2}$ are based on the same building block and have the same needle-like morphology [33]. Similar whisker-like structures are also observed on the Ti-B compounds by micropyretic synthesis [34]. Yang et al. [34] show that the morphologies of the combustion synthesized Ti-B compounds varied from flake type to whisker type, depending on boron content.

\subsection{Robust Check of the Error of the Measured Sizes and Temperatures. Arrhenius-type plot of size and temperature is used to calculate the activation energy of Ti-B reaction. As compared with the reported experimental value, the calculated activation energy can be used to verify the accu- racy of the measured size and temperature in this study. The diameters of the TiB whisker-type structures are noted to increase when the combustion temperature is raised by changing the composition. The correlation of the whisker diameter with the temperature is thus used to calculate}




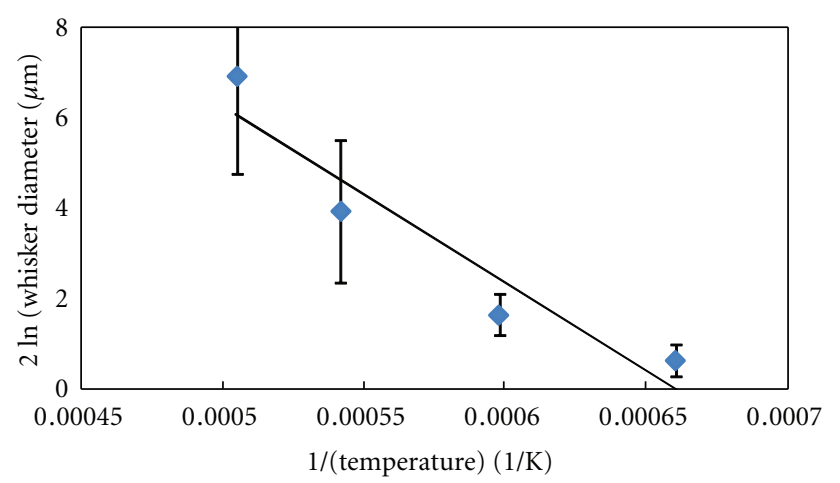

Figure 6: Arrhenius-type plot of the TiB whisker diameter and combustion temperature.

the activation energy [35-38]. The general relation between the whisker/grain size and the temperature is expressed as $[35,36]$

$$
2 \ln (D)=-\frac{E}{R T}+\text { constant }
$$

where $D$ is the grain size or whisker diameter, $E$ is the activation energy for the whisker growth, $T$ is the combustion temperature, and $R$ is the universal constant (= $8.314 \mathrm{~J} / \mathrm{mole} / \mathrm{K})$. As employing (4), the activation energy for TiB whisker growth is determined from the plot of 2 $\ln (D)$ and $1 / T$. From an Arrhenius-type plot in Figure 6, the activation energy for the whisker growth is calculated to be $231 \mathrm{KJ} /$ mole. As compared with the reported values for TiB combustion, $230 \mathrm{KJ} / \mathrm{mole}$ [39] or $251 \mathrm{KJ} / \mathrm{mole}$ [40], which was approached from the combustion wave velocity and temperature profile investigation, respectively, the calculated value for the whisker growth is in good agreement with the reported values for the Ti-B combustion, verifying the accuracy of the measured size and temperature in this study.

In addition, from the Arrhenius-type plot of diameter and measure combustion temperature, we can also forecast the reaction temperature for the nanosize whisker. Note from the calculated results that the $<10 \mathrm{~nm}$ TiB whisker starts to form when the combustion temperature is decreased to $1500 \mathrm{~K}$.

\section{Summary and Conclusions}

Processing of $\mathrm{TiB}$ compound by micropyretic synthesis is carried out in this study. Experimental study and numerical simulation are both used to investigate the correlation of the processing parameters on the microstructure of the synthesized products. It is noted that nanosize $\mathrm{TiB}$ whisker is expected to occur when the combustion temperature is lower but higher than the extinguish temperature. The results generated in the numerical calculation can be used as a helpful reference to select properly the processing route of producing nanosize features product. The Arrhenius-type plot of size and temperature is also used to calculate the activation energy of $\mathrm{TiB}$ reaction. The calculation activation energy is in a good appointment with the reported value, verifying that the accuracy of the experimental measures of the grain size in this study. In addition, the Arrhenius-type plot can be used to forecast the combustion temperature for producing nanosize TiB whisker.

\section{Nomenclature}

$C_{p}$ : Heat capacity, $\mathrm{Jkg}^{-1} \mathrm{~K}^{-1}$

E: Activation energy, Jmole ${ }^{-1}$

$h$ : Surface heat transfer coefficient, $\mathrm{Jm}^{-2} \mathrm{~K}^{-1} \mathrm{~s}^{-1}$

$K_{o}$ : Preexponential factor, $\mathrm{s}^{-1}$

Q: Exothermic heat of reaction, $\mathrm{Jmole}^{-1}$

$R$ : Universal gas constant, Jmole ${ }^{-1} \mathrm{~K}^{-1}$

$T$ : Temperature, $\mathrm{K}$

$T_{o}$ : Initial temperature of the unreacted compact, $\mathrm{K}$

$t$ : Time, $\mathrm{s}$

$z$ : Dimensional coordinate, $\mathrm{m}$

$d$ : Diameter of the specimen, $\mathrm{m}$.

\section{Greek Letters}

$\kappa$ : Thermal conductivity, $\mathrm{Jm}^{-1} \mathrm{~s}^{-1} \mathrm{~K}^{-1}$

$\Phi$ : Reaction rate, $\mathrm{s}^{-1}$

$\rho:$ Density, $\mathrm{km}^{-3}$

$\eta$ : Reacted fraction.

\section{References}

[1] Y. S. Naiborodenko, V. I. Itin, and K. V. Savitskii, "Use of combustion and thermal explosion for the synthesis of intermetallic compounds and their alloys," Powder Metallurgy and Metal Ceramics, vol. 7, no. 91, pp. 562-567, 1970.

[2] Z. A. Munir and J. B. Holt, "The combustion synthesis of refractory nitrides-part 1. Theoretical analysis," Journal of Materials Science, vol. 22, no. 2, pp. 710-714, 1987.

[3] Z. A. Munir, "Synthesis of high temperature materials by selfpropagating high-temperature combustion methods," American Ceramic Society Bulletin, vol. 67, no. 2, pp. 342-349, 1988.

[4] H. P. Li and J. A. Sekhar, "Influence of the reactant size on the micropyretic synthesis of NiAl intermetallic compounds," Journal of Materials Research, vol. 10, no. 10, pp. 2471-2480, 1995.

[5] Y. S. Naiborodenko and V. I. Itin, "Gasless combustion of metal powder mixtures-1. Mechanism and details," Combustion, Explosion, and Shock Waves, vol. 11, no. 3, pp. 293-300, 1975.

[6] A. G. Merzhanov and B. I. Khaikin, "Theory of combustion waves in homogeneous media," Progress in Energy and Combustion Science, vol. 14, no. 1, pp. 1-98, 1988.

[7] V. M. Shkiro and G. A. Nersisyan, "Structure offluctuations occurring in the burning of tantalum-carbon mixtures," Combustion, Explosion, and Shock Waves, vol. 14, no. 1, pp. 121122, 1978.

[8] I. P. Borovinskaya, A. G. Merzhanov, N. P. Novikov, and A. K. Filonenko, "Gasless combustion of mixtures of powdered transition metals with boron," Combustion, Explosion, and Shock Waves, vol. 10, no. 1, pp. 2-10, 1974.

[9] S. Hwang, A. S. Mukasyan, A. S. Rogachev, and A. Varma, "Combustion wave microstructure in gas-solid reaction systems: experiments and theory," Combustion Science and Technology, vol. 123, no. 1-6, pp. 165-184, 1997. 
[10] J. A. Sekhar, H. P. Li, and G. K. Dey, "Decay-dissipative Belousov-Zhabotinsky nanobands and nanoparticles in NiAl," Acta Materialia, vol. 58, no. 3, pp. 1056-1073, 2010.

[11] H. P. Li and J. A. Sekhar, "Belousov-Zhabotinsky dissipative reactions in Ti-B and Ni-Al alloy systems," Acta Materialia, vol. 57, no. 18, pp. 5430-5444, 2009.

[12] M. G. Lakshmikantha and J. A. Sekhar, "Influence of multidimensional oscillating combustion fronts on thermal profiles," Journal of Materials Science, vol. 28, no. 23, pp. 64036408, 1993.

[13] M. Lakshmikantha and J. A. Sekhar, "Analytical modeling of the propagation of a thermal reaction front in condensed systems," Journal of the American Ceramic Society, vol. 77, no. 1, pp. 202-210, 1994.

[14] H. P. Li, S. B. Bhaduri, and J. A. Sekhar, "Metal-ceramic composites based on the Ti-B-Cu porosity system," Metallurgical Transactions A, vol. 23, no. 1, pp. 251-261, 1992.

[15] H. P. Li and J. A. Sekhar, "Processing maps for the micropyretic synthesis of structural composites and intermetallics," in Proceedings of the 1st International Conference on Advanced Synthesis of Engineered Materials, J. J. Moore, E. J. Lavernia, and F. H. Froes, Eds., pp. 25-31, 1993.

[16] H. P. Li and J. A. Sekhar, "Rapid solidification by unstable combustion synthesis," Journal of Materials Research, vol. 8, no. 10 , pp. 2515-2523, 1993.

[17] O. K. Dey and J. A. Sekhar, "Micropyretic synthesis of tough nial alloys," Metallurgical and Materials Transactions B, vol. 28, no. 5, pp. 905-918, 1997.

[18] G. He, J. Eckert, W. Löser, and L. Schultz, "Novel Ti-base nanostructure-dendrite composite with enhanced plasticity," Nature Materials, vol. 2, no. 1, pp. 33-37, 2003.

[19] J. Ning, G. Xiao, L. Wang, B. Zou, B. Liu, and G. Zou, "Facile synthesis of magnetic metal ( $\mathrm{Mn}, \mathrm{Fe}, \mathrm{Co}$, and $\mathrm{Ni}$ ) oxide nanocrystals via Cation-exchange reaction," Nanoscale, vol. 3, no. 2, pp. 741-745, 2011.

[20] H. A. Lee, M. Imran, N. A. Monteiro-Riviere, V. L. Colvin, W. W. Yu, and J. E. Riviere, "Biodistribution of quantum dot nanoparticles in perfused skin: evidence of coating dependency and periodicity in arterial extraction," Nano Letters, vol. 7, no. 9, pp. 2865-2870, 2007.

[21] H. H. Huang, F. B. Wu, J. W. Lee, and L. C. Chang, "Microstructure and corrosion behavior of Ni-Alloy/CrN nanolayered coatings," Journal of Nanomaterials, vol. 2011, Article ID 137498, 6 pages, 2011.

[22] N. Lin, J. Huang, P. R. Chang, D. P. Anderson, and J. Yu, "Preparation, modification, and application of starch nanocrystals in nanomaterials: a review," Journal of Nanomaterials, vol. 2011, Article ID 573687, 13 pages, 2011.

[23] Annual Book of ASTM Standard, ASTM, Philadelphia, PA, USA, 1989.

[24] E. A. Brandes and G. B. Brook, Smithells Metals Reference Book, Butterworth-Heinemann, 1992.

[25] T. S. Azatyan, V. M. Mal'tsev, A. G. Merzhanov, and V. A. Seleznev, "Combustion wave propagation mechanism in titanium-boron mixtures," Combustion, Explosion, and Shock Waves, vol. 16, no. 2, pp. 163-167, 1980.

[26] G. V. Samsonov and I. M. Vinitskii, Handbook of Refractory Compounds, IFI/Plenum, New York, NY, USA, 1980.

[27] Z. A. Munir and U. Anselmi-Tamburini, "Self-propagating exothermic reactions: the synthesis of high-temperature materials by combustion," Materials Science Reports, vol. 3, no. 7-8, pp. 277-365, 1989.

[28] V. M. Shkiro, V. N. Doroshin, and I. P. Borovinskaya, "Concentration structure of the combustion wave in the titanium- carbon system," Combustion, Explosion, and Shock Waves, vol. 16, no. 4, pp. 370-374, 1980.

[29] E. A. Nekrasov, Y. M. Maksimov, M. K. Ziatdinov, and A. S. Shteinberg, "Effect of capillary spreading on combustion-wave propagation in gas-free system," Combustion, Explosion, and Shock Waves, vol. 14, no. 5, pp. 575-581, 1978.

[30] J. Zhu, A. Kamiya, T. Yamada, W. Shi, K. Naganuma, and K. Mukai, "Surface tension, wettability and reactivity of molten titanium in Ti/yttria-stabilized zirconia system," Materials Science and Engineering A, vol. 327, no. 2, pp. 117-127, 2002.

[31] R. A. Andrievskii, A. T. Pak, and I. F. Baiman, "Some features of structure formation and density variation in thermally reactive titanium-boron powder mixtures," Soviet Powder Metallurgy and Metal Ceramics, vol. 28, no. 9, pp. 669-671, 1989.

[32] Y. Hashimoto, S. Ohrnori, and K. Kohyama, "Reaction-sintering of Cu-Ti-B alloys," Journal of the Japan Society of Powder and Powder Metallurgy, vol. 33, no. 6, pp. 302-305, 1986.

[33] M. E. Hyman, C. McCullough, J. J. Valencia, C. G. Levi, and R. Mehrabian, "Microstructure evolution in tial alloys with b additions: conventional solidification," Metallurgical Transactions A, vol. 20, no. 9, pp. 1847-1859, 1989.

[34] W. Y. Yang, H. C. Yi, and A. Petric, "Microstructure of the $\mathrm{Ti} 3 \mathrm{Al}(\mathrm{Nb}) / \mathrm{TiB}$ composite produced by combustion synthesis," Metallurgical and Materials Transactions A, vol. 26, no. 11, pp. 3037-3043, 1995.

[35] C. P. Cameron and R. Raj, "Grain-growth transition sintering of colloidally prepared alumina powder compacts," Journal of the American Ceramic Society, vol. 71, no. 12, pp. 1031-1035, 1988.

[36] R. E. Read-Hill, Physical Metallurgy Principle, 1992.

[37] R. M. German, Powder Metallurgy Science, 1984.

[38] Y. M. Chiang and W. D. Kingery, "Grain-boundary migration in nonstoichiometric solid solutions of magnesium aluminate spinel: I. Grain growth studies," Journal of the American Ceramic Society, vol. 72, no. 2, pp. 271-277, 1989.

[39] T. S. Azatyan, V. M. Mal'tsev, A. G. Merzhanov, and V. A. Seleznev, "Combustion wave propagation mechanism in titanium-boron mixtures," Combustion, Explosion, and Shock Waves, vol. 16, no. 2, pp. 163-167, 1980.

[40] A. A. Zenin, A. G. Merzhanov, and G. A. Nersisyan, “Thermal wave structure in SHS processes, using the example of boron synthesis," Combustion, Explosion, and Shock Waves, vol. 17, pp. 63-71, 1931. 

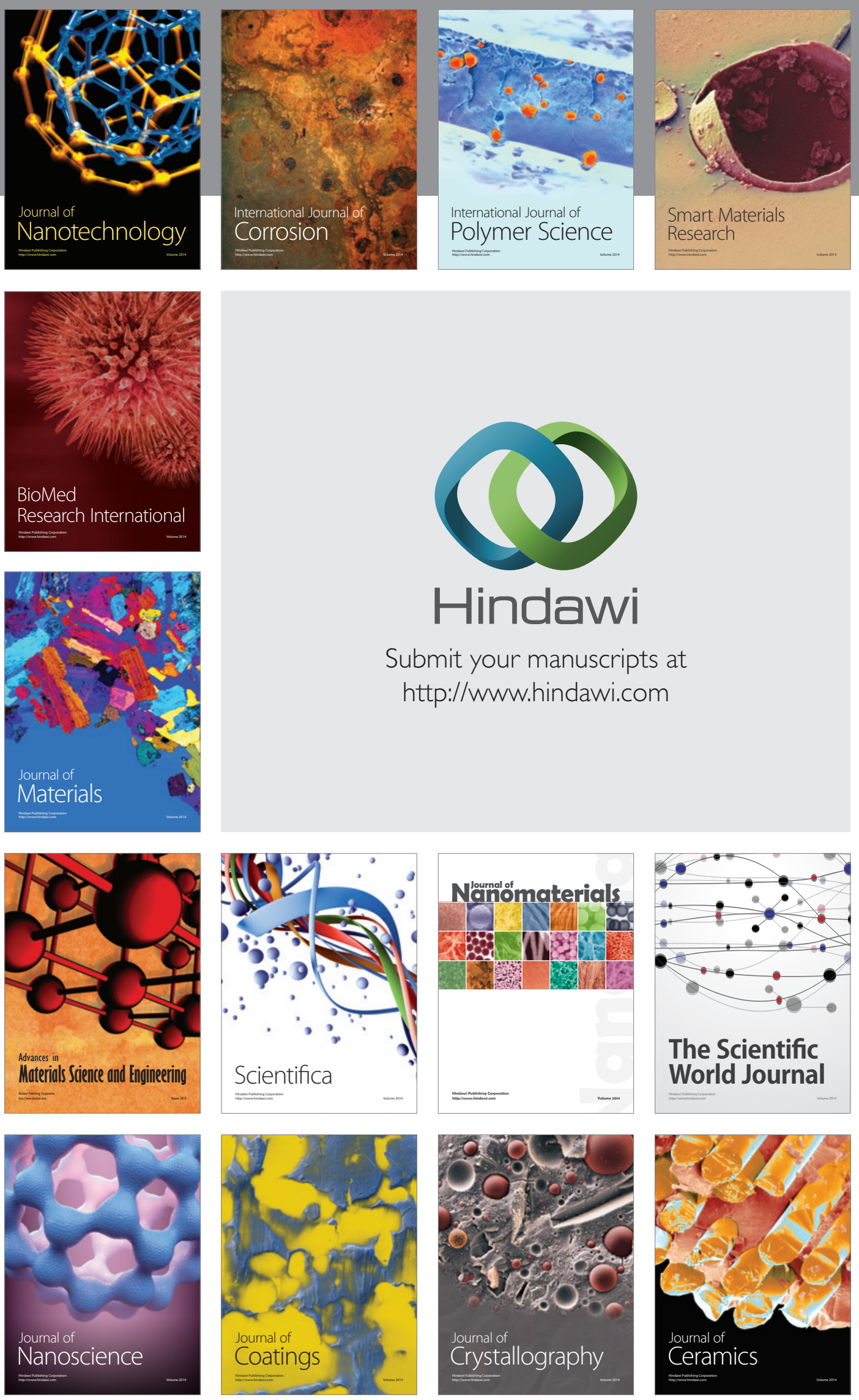

The Scientific World Journal

Submit your manuscripts at

http://www.hindawi.com

\section{World Journal}

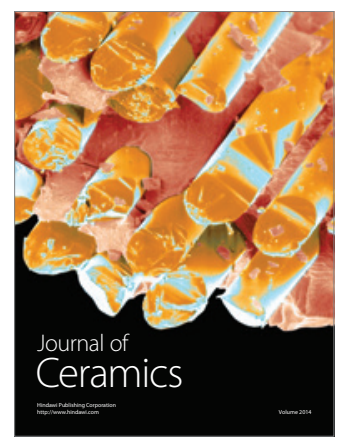

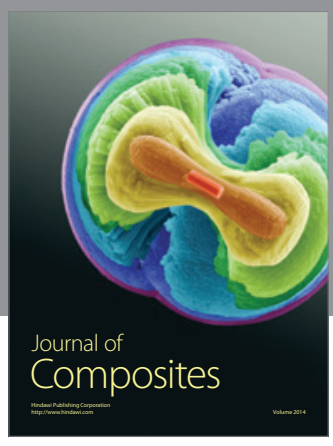
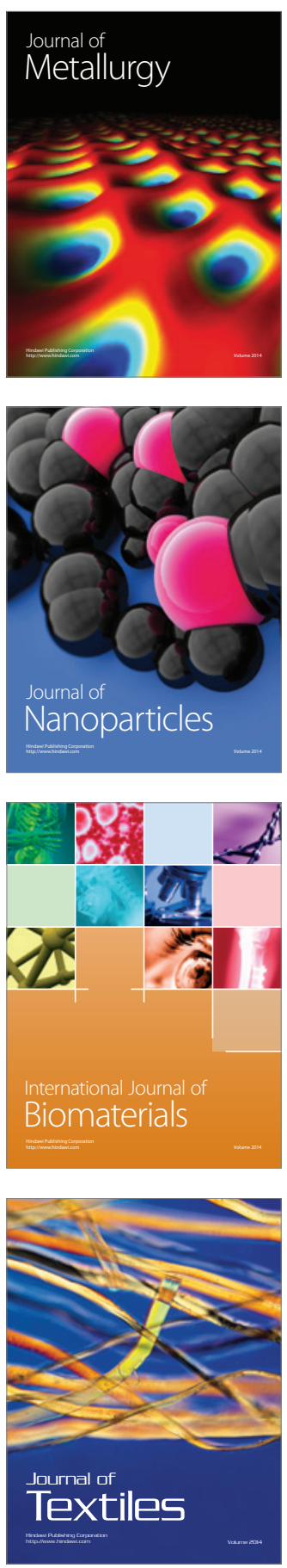